DOI: $10.7242 / 2658-705 X / 2019.4 .2$

УДК 539.3

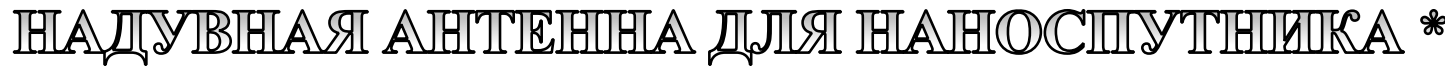

\author{
Л.А. Комар, Институт механики сплошных сред УрО РАН \\ А.Г. Пелевин, Пермский государственный национальный исследовательский университет \\ И.В. Осоргина, Пермский государственный нациинальный исследовательский университет \\ В.Г. Гилев, Пермский государственный национальный исследовательский университет \\ А.Л. Свистков, Институт механики сплошных сред УрО РАН
}

Актуальной проблемой для выводимых на околоземную орбиту наноспутников является создание надежной надувной антенны. Она должна иметь малый размер, а после выведения на орбиту принимать заданную форму. В данной работе предлагается вариант каркасно-надувной антенны, в которой каркас изготовляется из препрега и отверждается на околоземной орбите. При этом сохраняются все достоинства надувных антенн (малый объем и масса, простота конструкции и надежность приведения в рабочее состояние, устойчивая связь на дальних расстояниях). Такой антенне не страшны удары малых частиц-пылинок, двигающихся с космическими скоростями. Отсутствует также необходимость в постоянной подкачке газа в надувные элементы антенны. Следовательно, не требуются механизмы, обеспечивающие регулировку подачи газа, дополнительные емкости с газом или емкости с химическими элементами для его получения.

В данной работе рассмотрены варианты выбора реакционной смеси для изготовления связующего препрега. Главным критерием подбора смеси является низкая летучесть ее компонентов и способность к горячему отверждению. Приведены результаты стратосфрерного полета воздушного шара с опытными образцами. Предложен вариант конструкции надувной антенны.

Ключевые слова: наноспутник, надувная антенна, препрег, отверждение, реакиионная смесь, испарение, полетный эксперимент, космос.

\section{Введение}

В настоящее время на околоземную орбиту запускается большое количество наноспутников. Одной из серьезных проблем в их работе является недостаточная эффективность антенн для передачи на Землю радиосигналов. Все они представляют собой раскладывающиеся металлические конструкции. Однако при использовании сложных раскладных конструкций возможны отказы; антенны зонтичного типа занимают много места в сложенном состоянии; простые штыревые антенны не обеспечивают желаемую производительность. Поэто-

* Исследования проведены при финансовой поддержке гранта РФФИ № 16-48-590844-p_a «Математическое моделирование технологии изготовления отверждаемой надувной антенны наноспутника на космической орбите». Полетный эксперимент и реологические исследования осуществлены в рамках совместной работы с проектом № C-26/793 «Разработка технологии создания пневматических отверждаемых крупногабаритных конструкций из полимер-композитных материалов в условиях открытого космоса», реализуемом при финансовой поддержке Министерства образования и науки Пермского края. 
му одним из возможных выходов является использование надувных антенн.

Преимуществом надувных антенн являются надежность приведения их в рабочее состояние, нужная геометрия отражателя (зеркала), малый объем в сложенном состоянии. Именно этими характеристиками обладает антенна, разработанная в Массачусетском технологическом институте. К сожалению, в условиях открытого космоса такие конструкции очень уязвимы. Они могут столкнуться с малым метеоритом, космической пылью, которая способна пробить их стенки и привести к утечке газа. Выход разработчики нашли в использовании специального порошка, который выделяет газ, как только давление в изделии снижается ниже определенной величины.

В данной работе рассматривается другой вариант сохранения длительного времени нужной геометрии антенны. Предлагается использовать для этого отверждаемый каркас из препрега. Изделие в свернутом состоянии помещается в наноспутник на земле. На орбите происходит надувание антенны. После этого должно произойти отверждение каркаса. При этом возникают вопросы, связанные с возможностью отверждения препрега без дополнительного подогрева только за счет солнечного излучения. Как проявится в данном процессе испарение компонентов реакционной смеси в условиях вакуума? Произойдет ли закипание реакционной смеси в открытом космосе? Какой будет продолжительность процесса? Какой живучестью будет обладать изделие во время хранения в ожидании запуска на околоземную орбиту?

Идея о возможности получения отвержденных препрегов в условиях открытого космоса для создания больших космических станций возникла в конце прошлого столетия и основоположником этой идеи является российский ученый А.В. Кондюрин [1]. Им была разработана технология отверждения препрегов в наземных лабораториях с условиями, максимально приближенными к условиям открытого космоса [2-4]. В дальнейшем, сотрудничая с иностранными учеными, российская группа исследователей показала, что отверждение композиционного материала в условиях открытого космоса позволит непосредственно на орбите изготавливать крупногабаритные конструкции [5].

В особый класс следует выделить исследования, связанные с моделированием разворачивания космических конструкций [6-12]. Работы пермских ученых направлены на изучение прогрева крупногабаритной оболочечной конструкции на околоземной орбите под действием солнечного излучения [13-15] и особенностей отверждения эпоксидных смол в вакууме [16-17]. Авторы работ [18-19] высказывают целесообразность использования принципа горячего отверждения реакционной смеси. В результате проведенных ими вычислительных экспериментов было установлено, что горячее отверждение возможно осуществить, если имеется тонкая алюминиевая пленка на поверхности препрега с наружной стороны надувного элемента антенны.

\section{Каркасно-надувная антенна}

С нашей точки зрения, в качестве удачного прототипа надувной антенны может служить конструкция, разработанная в Массачусетском технологическом институте, которая успешно проявила себя в испытаниях на земле. Особенностью антенны является то, что для ее надувания и поддержания долгое время в рабочем состоянии разработчики используют специальный порошок, который выделяет газ при низком давлении. По замыслу авторов, наличие достаточного количества порошка на спутнике должно обеспечивать подкачку новой порции газа в случае утечки его в космос.

В ИМСС УрО РАН предложено усовершенствовать вариант антенны, отказавшись от использования порошка и добавив отверждаемый каркас из полосок препрега. Задача этого каркаса состоит в том, чтобы в отвержденном состоянии он сохранял требуемую форму антенны. В этом случае отпадает необходимость поддерживать давление газа в надувном элементе. 
Компьютерные эксперименты позволили определить температуру каркаса на околоземной орбите. Поскольку антенна имеет сложную геометрию, падение потока солнечного излучения на поверхность отверждаемого каркаса происходит под разными углами и приводит к существенным отличиям температурного режима в разных частях антенны. Частично выравнивание температуры может быть достигнуто использованием материала для оболочки каркаса, имеющего высокую теплопроводность. Наиболее эффективным, с точки зрения выравнивания температуры, является вращение наноспутника. В этом случае возможно добиться относительно равномерного нагрева каркаса до температур, необходимых для горячего отверждения. Отличительной особенностью предлагаемой нами надувной антенны является наличие каркаса из препрега, имеющего тонкое металлическое покрытие, закрывающее оболочку снаружи. Пример такой конструкции показан на рис. 1.

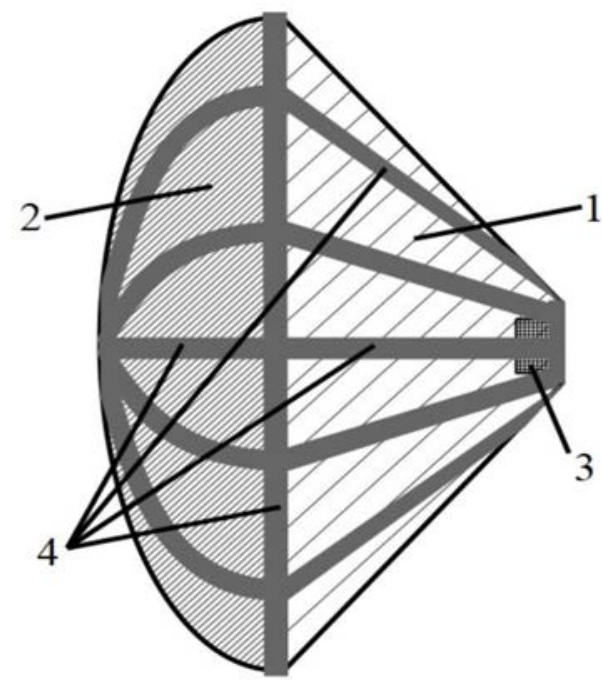

Рис. 1. Надувная антенна для космических аппаратов: 1 - проницаемая для радиоволн полимерная оболочка, 2 - полимерная оболочка с металлизированным покрытием,

3-nатч-антенна, 4-отверждаемый каркас

Надувная антенна содержит полимерную оболочку. Часть 1 этой оболочки изготовлена из проницаемого для радиоволн материала. Часть 2 имеет металлизированное покрытие, которое отражает радиоволны, и форму параболоида враще- ния, в фокусе которого установлена патчантенна, отмеченная элементом конструкции с цифрой 3. Полимерная оболочка скреплена с отверждаемым каркасом 4.

Антенна находится в спутнике при выводе на орбиту в сложенном виде и приводится в рабочее состояние с помощью заполнения ее газом. При этом каркас антенны находится в мягком состоянии и разворачивается вместе с оболочкой антенны. Позже должно происходить отверждение препрега в каркасе в результате нагрева солнечным излучением и тепловым излучением от поверхности Земли.

Проведенные компьютерные эксперименты показали, что для достижения необходимой для отверждения температуры следует поместить препрег в тонкую металлическую оболочку - алюминиевую фольгу. Она имеет высокую отражающую способность, то есть нагрев материала будет происходить в такой оболочке медленнее, чем в ее отсутствии. Однако у алюминиевой фольги низкий коэффициент излучения, она медленно излучает тепло. В результате материал может нагреваться под действием теплового излучения на существенно большую величину, достаточную для осуществления горячего отверждения. Кроме того, тонкое металлическое покрытие каркаса служит для исключения прилипания неотверждённого препрега друг к другу и к оболочке надувного элемента антенны во время транспортировки. После отверждения каркас антенны становится жёстким и сохраняет форму рабочей поверхности антенны при улетучивании газа внутри оболочки из-за его диффузии через надувную оболочку, повреждения ее космической пылью и микрометеоритами, а также через элементы крепления к корпусу.

\section{Исследование возможности}

использования реакционной смеси горячего отверждения для изготовления препрега

При обычной температуре и давлении химическая реакция отверждения не должна осуществляться. Выполнение этого тре- 
бования необходимо для того, чтобы конструкцию можно было довести до космодрома и хранить ее на складе в ожидании запуска наноспутника. На околоземной орбите, после разворачивания антенны, должен начаться процесс отверждения.

На первом шаге исследования была выбрана реакционная смесь для изготовления препрега, состоящая из смолы ЭД-20 с отвердителем изо-МТГФА (изометилтетрагидрофталевый ангидрид). Данный состав имеет высокие физико-механические характеристики и применяется для пропитывания тканей. Это реакционная смесь горячего отверждения. Химическая реакция отверждения происходит при температуре $150{ }^{\circ} \mathrm{C}$. Эксперименты осуществлены при разных температурах. За основу была взята температуpa, при которой можно наблюдать медленное течение процесса отверждения (около $80^{\circ} \mathrm{C}$ ) и рекомендованная температура отверждения $\left(150^{\circ} \mathrm{C}\right)$.

Кроме этого, рассматривался двухстадийный процесс, в котором часть времени образец находится при температуре $80{ }^{\circ} \mathrm{C}$, остальную часть времени при температуре $150{ }^{\circ} \mathrm{C}$. Хроматография эпоксидной смолы ЭД-20 показала существование двух пиков, относящихся к наличию «длинных» и «коротких» молекул. Установлено, что на 100 коротких молекул смолы приходится 8 длинных молекул, содержащих гидроксильные группы. Эти гидроксильные группы являются инициаторами химической реакции. Однако в условиях вакуума экспериментальное исследование отверждения смеси смолы ЭД-20 с отвердителем изо-МТГФА не принесли удовлетворительных результатов из-за высокой летучести отвердителя.

Следующей реакционной смесью стала смесь, состоящая из эпоксидной смолы ЭД-20 и отвердителя ТЭАТ-1 (триэтаноламинтитаната). Отвердитель ТЭАТ-1 является катализатором химической реакции: он не входит в состав конечного продукта, хотя и участвует в промежуточных реакциях. Количество отвердителя ТЭАТ-1 влияет на скорость химической реакции, но мало изменяет механические свойства конечного материала. Важной особенностью материала была низкая летучесть компонентов в условиях вакуума. В процессе работы предложена математическая модель, учитывающая кинетику химической реакции отверждения смеси смолы ЭД-20 и отвердителя ТЭАТ-1. Сравнение теоретических и экспериментальных значений показано на рис. 2. Новизной модели является идея рассмотрения при анализе химической реакции не отдельных молекул, а выделенных специальным образом групп атомов [17].

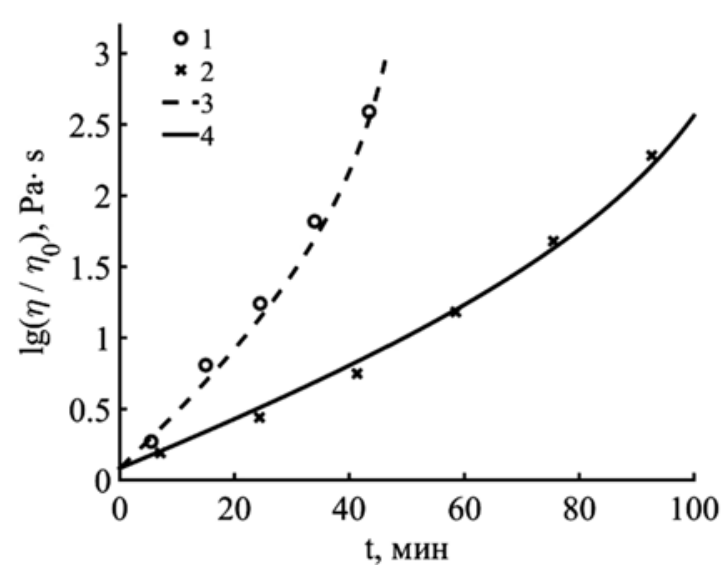

Рис. 2. Зависимость изменения вязкости во времени: 1 - результаты экспериментов, выполненных при температуре $140{ }^{\circ} \mathrm{C}$,

2 - при температуре $100^{\circ} \mathrm{C}, 3$ - результаты математического моделирования изменения вязкости при температуре $140^{\circ} \mathrm{C}$, 4 - при температуре $100{ }^{\circ} \mathrm{C}$

Установлено, что препрег становится жестким после 2 часов отверждения - при температуре $100{ }^{\circ} \mathrm{C}$, через 1,5 часа - при температуре $120^{\circ} \mathrm{C}$, через 1 час при температуре $140{ }^{\circ} \mathrm{C}$. Химическая реакция в препреге продолжается и закончится через несколько часов. Это означает, что за два оборота вокруг Земли (с учетом захода в тень от планеты) созданная из препрега и отвержденная в космосе антенна станет жесткой и разгерметизация надувного элемента антенны (в результате удара микрочастиц или других факторов) не приведет к потере ее работоспособности. Также она станет нечувствительна к поворотам наноспутника, 
которые уже не смогут вызвать появление складок в надувной конструкции.

Рассмотренная смесь смолы ЭД-20 и отвердителя ТЭАТ-1 показала удовлетворительные свойства по времени и температуре отверждения. Однако оказалась, что она не обладает высокой степенью «живучести»: хранение препрега при комнатной температуре через 14 дней приводит к увеличению его жесткости в 4 раза, что ставит под сомнение возможность использования таких препрегов, даже если наноспутник хранится на космодроме меньше двух недель.

Более перспективной с точки зрения длительной жизнеспособности оказалось реакционная смесь ЭНФБ. Исследования показали, что реакция отверждения при комнатной температуре этой смеси идет в два раза медленнее, чем у реакционной смеси с эпоксидной смолой ЭД-20 и отвердителем ТЭАТ-1. При хранении в холодильнике при температуре $5^{\circ} \mathrm{C}$ процесс отверждения замедляется еще в два раза. Несмотря на то, что смесь ЭНФБ используется в авиационной промышленности, особенности ее поведения в условиях вакуума ранее не рассматривались. Смесь показала в экспериментах удовлетворительные свойства. Следует иметь в виду, что на процесс отверждения может влиять космическое излучение на околоземной орбите. Чтобы выяснить, как поведет себя препрег со связующим ЭНФБ в условиях, более близких к космическим, был осуществлен стратосферный эксперимент.

\section{Исследование механических свойств препрегов после нахождения их в стратосфере}

Экспериментальное моделирование совокупности всех факторов открытого космоса в лабораторных условиях невозможно, тогда как натурные космические эксперименты с отверждением эпоксидных композиций на орбите Земли достаточно сложны и дороги. Поэтому одним из проведенных экспериментов стал эксперимент с образцами, которые были запущены в полет в стратосфере на воздушном шаре (рис. 3).

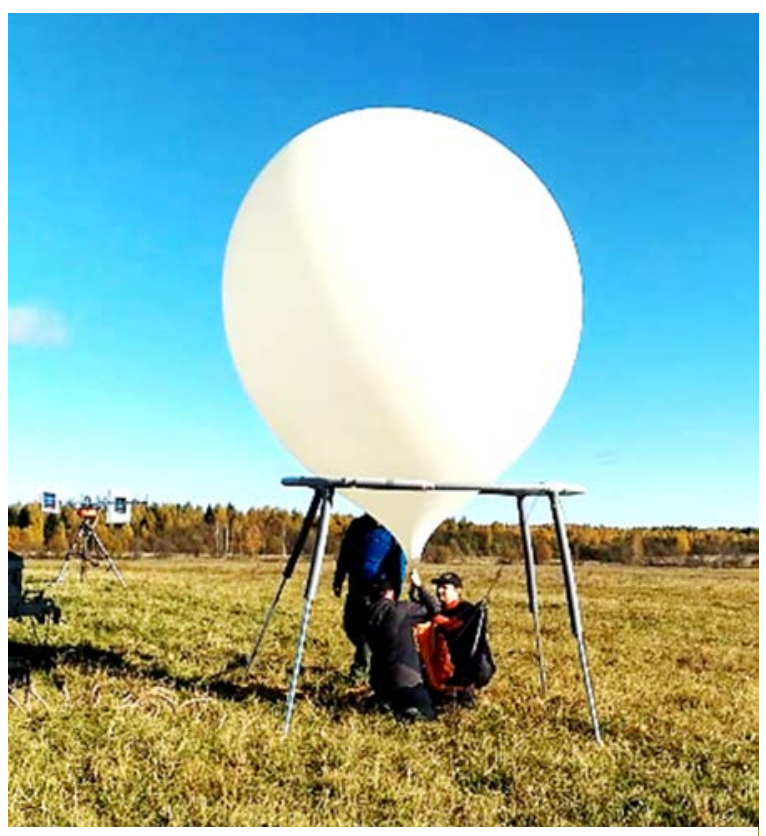

Рис. 3. Подготовка к запуску воздушного шара, наполненного гелием. В стратосфере

он может раздуться до 10 м в диаметре

Запуск шара осуществлялся при благоприятных погодных условиях. Траектория полета шара показана на рис. 4. Если направление движения в основном выдерживалось, то скорость движения то немного ускорялась, то замедлялась.

Обработанные данные полетного эксперимента показали следующее. Максимальная высота подъема шара равна 32 км (рис. 5). Длительность полета воздушного шара составляла 100 минут. На высоте больше 11 км шар находился 54 минуты. Это часть атмосферы, в которую проникают большое количество космических излучений, которые не достигают поверхности Земли. Давление воздуха на высоте больше 11 км изменялось от 0,023 МПа до 0,001 МПа (рис. 6). У поверхности Земли оно было равным 0,101 МПа. Во время полета температура образцов на высоте более 11 км изменялась в интервале от -58 до $24{ }^{\circ} \mathrm{C}$ (рис. 7). На рисунках синие вертикальные линии отмечают моменты времени, соответствующие высоте 11 км, красные - 25 км. На высоте 20-25 км меняется характер стратосферы. Она содержит 90\% озона, который образуется вследствие воздействия солнечной радиации и ультрафиолетового излучения на молекулы газа, которые диссоциируют на атомы. 


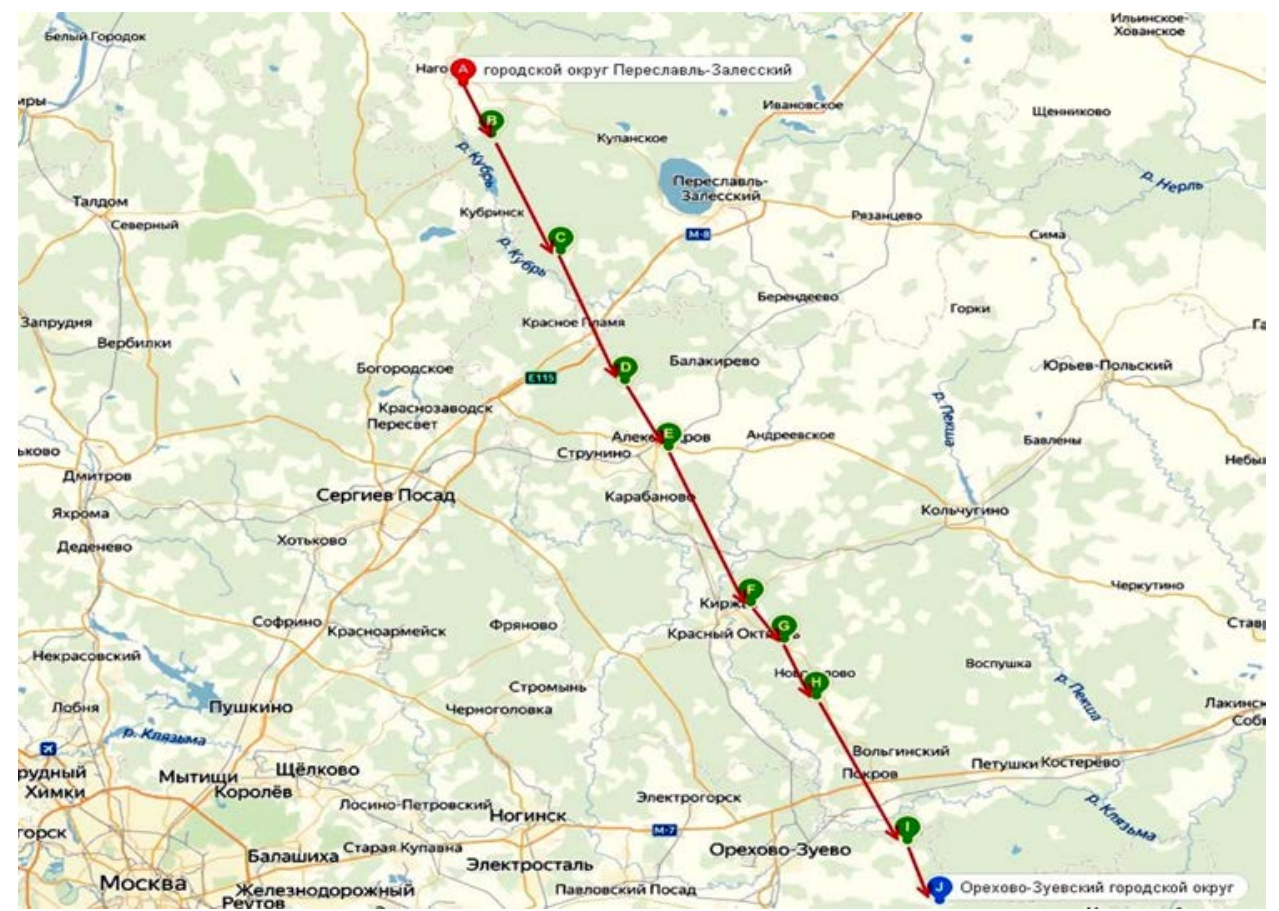

Рис. 4. Траектория полета шара, время полета, мин.: A-0; B-10; C-20; D-30; E-35; F- 57; G - 70; H-80; I- 90; J- 99

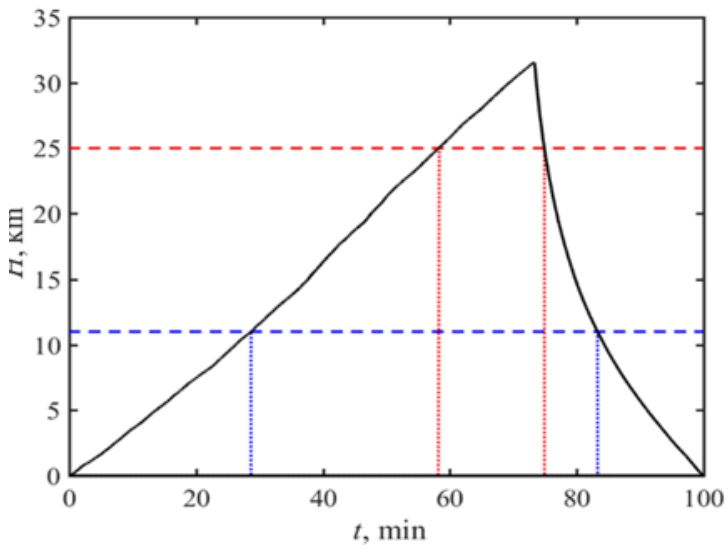

Рис. 5. Зависимость высоты от длительности полета воздушного шара

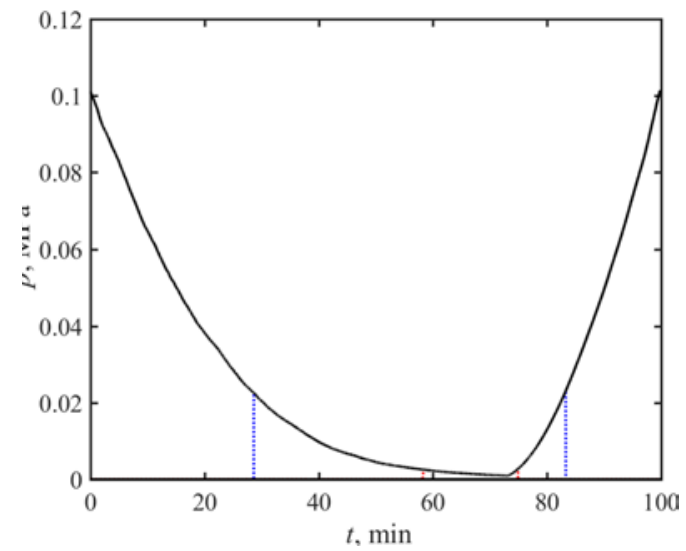

Рис. 6. Зависимость атмосферного давления от длительности полета воздушного шара

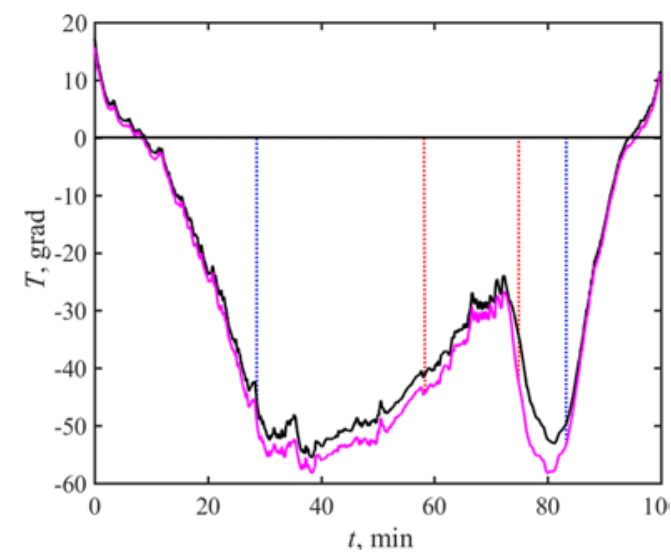

Рис. 7. Изменение температурь

в образцах в зависимости от времени полета воздушного шара. Измерения проводились 
Образцы для отверждения представляли собой препреги на основе полиамидной стропы и связующего ЭНФБ. Половина заготовленных образцов из препрега не участвовала в полетном эксперименте. Она хранилась в кассете в наземных условиях и рассматривались как контрольная партия. Вторая половина была размещена в кассете на воздушном шаре (рис. 8). Все время кассеты находились рядом друг с другом за исключением времени полета шара, когда контрольная партия была помещена в автомобиль, который отслеживал полет и возвращал шар в Москву.

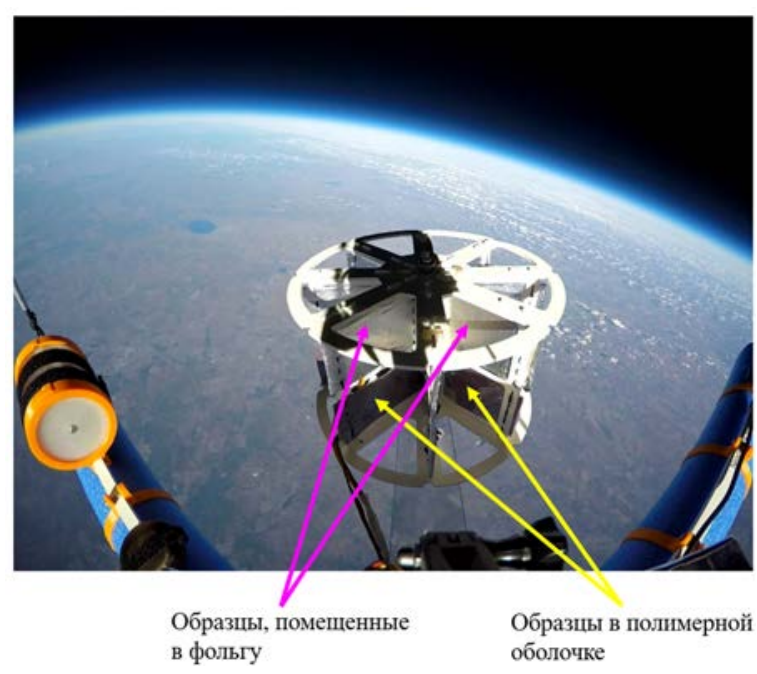

Рис. 8. Снимок кассеть с образиами на максимальной высоте полета воздушного шара

Следует заметить, что низкая температура атмосферы во время полета и то обстоятельство, что образцы были помещены в оболочку из фольги, препятствовали испарению компонентов реакционной смеси. Низкое давление воздуха приводит к тому, что концентрация молекул окружающего газа невелика (в частности озона). То есть изменения в образцах происходили, скорее всего, под действием излучений из космоса, которые проникают в стратосферу, но не доходят до поверхности Земли.

Исследование старения контрольных и полетных образцов осуществлялось путем измерения роста жесткости препрегов в экспериментах на трехточечный изгиб. Установлено, что полетные образцы всегда показывали жесткость на 23-25\% выше, чем жесткость контрольных образцов.
Объяснение может быть в следующем. Во всех образцах (контрольных и полетных) при дальнейшем их хранении при комнатной температуре происходит медленный рост глобул, причем с одинаковой скоростью. Но количество глобул разное. Во время полета в стратосфере появилось больше центров, из которых начался рост глобул (появилось больше инициаторов реакции отверждения). Можно ожидать, что в условиях космоса процесс отверждения может идти быстрее за счет появления дополнительных центров роста глобул.

\section{Реологические эксперименты}

Важным является анализ начала процесса разворачивания надувной отверждаемой конструкции, когда связующее находится в вязкотекучем состоянии. Чем ниже вязкость связующего, тем легче осуществить разворачивание надувной конструкции. В процессе работы по проекту проведены исследования механических свойств реакционной смести на стадии отверждения. Наиболее интересные результаты получены при сдвиговом деформировании исходного материала с разными амплитудами. Очень информативным показателем в этих экспериментах является угол сдвига фаз. Если он равен нулю, то мы имеем дело с упругой средой. Если он равен 90 градусам, то рассматриваемая среда является вязкой жидкостью. Если угол сдвига фаз имеет промежуточное значение, то среда является вязкоупругой жидкостью. Она проявляет одновременно и упругие свойства (деформируются глобулы, длинные клубки макромолекул), и способна течь, как вязкая жидкость. В основе течения среды лежит изменение взаимного расположения центров масс молекул и глобул в материале.

Установлено, что зависимость угла сдвига фаз от комплексной вязкости незначительно зависит от температуры проведения эксперимента в интервале от 100 до $140{ }^{\circ} \mathrm{C}$. Связано это с тем, что обе эти характеристики зависят только от одного фактора: количества и размеров глобул в отверждаемой смеси. Наиболее интерес- 
ный результат обнаружен при исследовании угла сдвига фаз в зависимости от амплитуды сдвиговых деформаций (которые изменялись по гармоническому закону). Реологические исследования трех реакционных смесей для горячего отверждения (смесь эпоксидной смолы ЭД-20 с отвердителем МТГФА, смесь ЭД-20 с отвердителем ТЭАТ-1, реакционная смесь ЭНФБ) показали, что на начальном этапе отверждения реакционные смеси ведут себя, как среда Бингама (рис. 9). При малых амплитудах достаточно заметным является проявление упругих свойств. При больших амплитудах это ньютоновская жидкость.

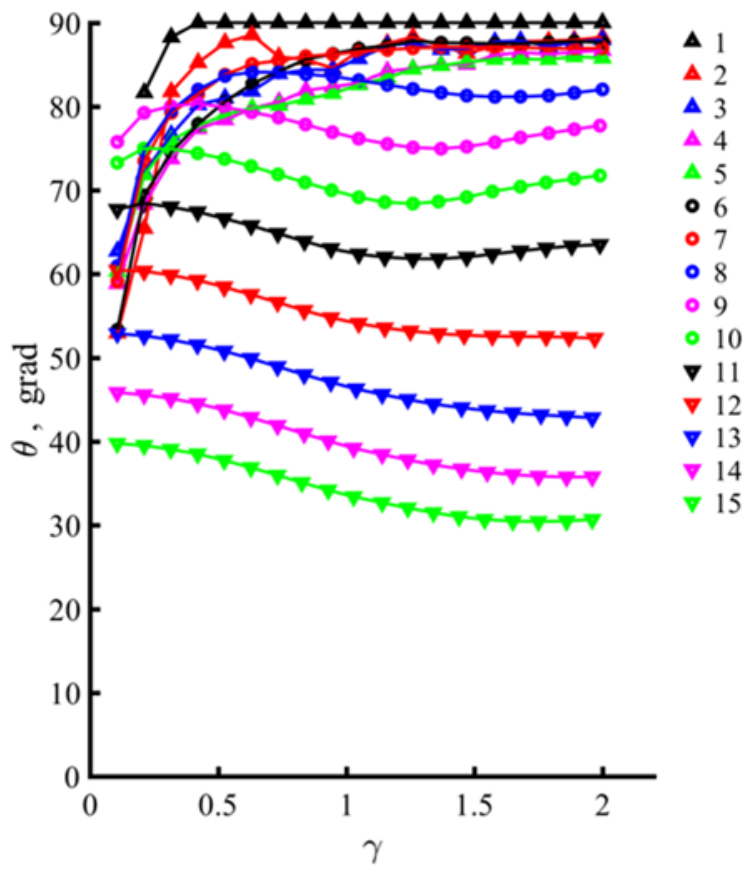

Рис. 9. Цифры у маркеров соответствуют разным сериям измерений зависимости угла сдвига фаз от амплитуды, полученные на реометре. Чем больше циирра, тем больше глубина реакции отверждения в момент измерения
Эксперименты по трехточечному деформированию образцов показали следующее. После нескольких десятков минут отверждения при температурах выше $100^{\circ} \mathrm{C}$ (от часа до двух часов для смеси эпоксидной смолы ЭД-20 с отвердителем ТЭТА-1). Отношение амплитуды сдвиговых напряжений к сдвиговой вязкости в реакционной смеси возрастает на 4 порядка. Это уже деформируемая среда. Начинает происходить разрушение материала при движении конуса реометра. Части разрушенного материала двигаются и трутся относительно друг друга. Реакционная смесь достигает состояния, в котором сильно затормаживаются массообменные процессы. Испарения не происходит.

\section{Заключение}

В рамках работы по проекту, поддержанному Российским фондом фундаментальных исследований, появилась идея создания нового типа конструкций антенны для наноспутников. Это каркасно-надувные антенны, в которых каркас создается из препрегов, отверждаемых на околоземной орбите. Установлено, что для осуществления горячего отверждения каркаса необходимо помещать его в легкодеформируемую, очень тонкую металлическую оболочку. Такая оболочка может быть изготовлена из алюминиевой фольги. Предложенные химические уравнения, математические модели и вычислительные эксперименты подтвердили возможность использования таких конструкций антенн для наноспутников на околоземной орбите. Для разогрева каркаса до требуемой температуры достаточно солнечного излучения и отраженного теплового излучения от Земли.

\section{Библиографический список}

1. Kondyurin A.V. Building the shells of large space stations by the polymerisation of epoxy composites in open space // International Polymer Science and Technology. -1998. - Vol. 25. № 4. - P. 78-80.

2. Kondyurin A., Lauke B., Richter E. Polymerization Process of Epoxy Matrix Composites under Simulated Free Space Conditions // High Performance Polymers. - 2004. - Vol. 16. - P. 163-175.

3. Kondyurin A.V., Lauke B., Vogel R., Nechitailo G. Kinetics of photocuring of matrix of composite material under simulated conditions of free space // Plasticheskie massi - 2007. - Vol. 11. - P. 50-55.

4. Кондюрин А.В., Нечитайло Г.С. Композиционный материал для надувных конструкций, фотополимеризующийся в условиях орбитального космического полета // Космонавтика и ракетостроение. - 2009. - Т. 3 (56). - С. 182-190. 
5. Kondyurin A.V., Bilek M. M. M., Kondyurina I.V., Vogel R., de Groh K.K. First Stratospheric Flight of Preimpregnated Uncured Epoxy Matrix // Journal of Spacecraft and Rockets. - 2016. - Vol. 53. - № 6. P. 1019-1027.

6. Block J., Straubel M., Wiedemann M. Ultralight deployable booms for solar sails and other large gossamer structures in space // Acta Astronautica. - 2011. - Vol. 68. - P. 984-992.

7. Babuscia A., Corbin B., Knapp M., Jensen-Clem R., Van de Loo M., Seager S. Inflatable antenna for cubesats: Motivation for development and antenna design // Acta Astronautica. - 2013. - Vol.91. - P. 322-332.

8. Gu Y., Duan B., Du J. The establishment and application of direct coupled electrostatic-structural field model in electrostatically controlled deployable membrane antenna // Acta Astronautica. - 2018. Vol. 146. - P. 185-191.

9. Лопатин А.В., Рутковская М.А. Обзор конструкций современных трансформируемых космических антенн (Часть 1) // Вестник Сибирского государственного аэрокосмического университета им. академика М.Ф. Решетникова. - 2007. - № 2 (15). - С. 51-57.

10. Wei J.Z., Tan H.F., Du X.W. Research progress of deployment dynamics of Space inflatable booms // Advances in mechanics. - 2008. - Vol. 38. - № 2. - P. 177-189.

11. Salama M., Kuо C. P., Lou M. Simulation of deployment dynamics of inflatable structures // AIAA Journal. - 2000. - Vol. 38. - № 12. - P. 2277-2283.

12. Freeland R.E., Bilyeu G.D., Veal G.R. Development of flight hardware for a large, inflatable-deployable antenna - experiment // Acta astronautica: 46 Int. Actron. Fed. Congress, Oslo, 2-6 Oct. - 1995. - Vol. 38. № 4-8. - P. 251-260.

13. Пестренин В.М., Пестренина И.В., Русаков С.В., Кондюрин А.В. Развертывание крупногабаритных оболочечных конструкций внутренним давлением // Механика композитных материалов. - 2015. T. 51. - № 5. - C. 889-898.

14. Гилев В.Г., Русаков С.В., Пестренин В.М., Пестренина И.В. Оценка жесткости развертываемой внутренним давлением цилиндрической композитной оболочки на начальном этапе полимеризации связующего // Вестник Пермского национального исследовательского политехнического университета. Механика. - 2018. - № 1. С. 93-99.

15. Наймушин А.П., Пестренин В.М., Пестренина И.В. Исследование прогрева крупногабаритной оболочечной конструкции на околоземной орбите под действием солнечного излучения // Вестник Пермского университета. Математика. Механика. Информатика. - 2013. - № 4 (23). - С. 51-54.

16. Свистков А.Л., Елисеева А.Ю., Кондюрин А.В. Математическая модель реакции отверждения ЭД-20 с отвердителем ТЭАТ-1 // Вестник Пермского университета. Физика. - 2019. - № 1. - С. 9-16.

17. Елисеева А.Ю., Свистков А.Л., Кондюрин А.В. Математическая модель реакции горячего отверждения препрега // Вестник Пермского университета. Физика. - 2017. - № 4 (38). - С. 19-25. https://doi.org/10.17072/1994-3598-2017-4-19-25.

18. Евлампиева С.Е., Беляев А.Ю., Мальцев М.С., Свистков А.Л. Анализ температурного режима отверждаемых надувных элементов антенн наноспутников // Механика композиционных материалов и конструкций. - 2017. - Т. 23. - С. 459-469 .

19. Garishin O.K., Svistkov A.L., Belyaev A.Yu., Gilev V.G. On the Possibility of Using Epoxy Prepregs for Carcass-Inflatable Nanosatellite Antennas // Materials Science Forum. - 2018. - Vol. 938. - P. 156-163.

\title{
INFLATABLE ANTENNA FOR A NANOSATELLITE
}

\author{
L.A. Komar $^{1}$, A.G. Pelevin ${ }^{2}$, I.V. Osorgina ${ }^{2}$, V.G. Gilev ${ }^{2}$, A.L. Svistkov ${ }^{1}$ \\ ${ }^{1}$ Institute of Continuous Media Mechanics UB RAS \\ ${ }^{2}$ Perm State National Research University
}

A topical problem for near-Earth orbit nanosatellites is the creation of a reliable inflatable antenna. The nanosatellite antenna should be small-sized and should take the given form after launching into orbit.

This paper proposes a technology for manufacturing an inflatable antenna from prepreg which is hardened in space orbit. At the same time, all the advantages of inflatable antennas are preserved (small volume and weight, simplicity of design and reliability of bringing into working condition, long-distance steady communication). Small dust particles moving at cosmic speeds cannot damage such an antenna. There is also no need to constantly pump gas into the inflatable elements of the antenna, hence there is no need for mechanisms to provide adjustment of gas supply, additional tanks with gas or tanks with chemical elements to obtain it. 
The process of selecting a suitable reaction mixture for pre-preg hardening is considered in the paper, the main criteria for the selection being low volatility of its components and hot hardening ability. The results of stratospheric balloon flight with pre-preg samples are given. The design of the inflatable antenna is proposed.

Keywords: nanosatellite, inflatable antenna, prepreg, hardening, reaction mixture, evaporation, flight experiment, space.

\section{Сведения об авторах}

Комар Людмила Андреевна, кандидат физико-математических наук, старший научный сотрудник, Институт механики сплошных сред УрО РАН - филиал Пермского федерального исследовательского центра УрО РАН (ИМСС УрО РАН), 614013, г. Пермь, ул. Академика Королева, 1; e-mail: komar@icmm.ru

Пелевин Александр Геннадьевич, младший научный сотрудник, Пермский государственный национальный исследовательский университет (ПГНИУ), 614990, Пермь, ул. Букирева, 15; e-mail: smile3k@yandex.ru

Осоргина Ирина Викторовна, ведущий инженер ПГНИУ; e-mail: osorgina@psu.ru

Гилев Валерий Григорьевич, кандидат физико-математических наук, доцент ПГНИУ; e-mail: gvg@psu.ru

Свистков Александр Львович, доктор физико-математических наук, заведующий лабораторией микромеханики структурно-неоднородных сред, ИМСС УрО РАН; e-mail: svistkov@icmm.ru 